\title{
ASPECTOS IMUNOLÓGICOS DAS LEISHMANIOSES DERMOTRÓPICAS E VISCEROTRÓPICAS
}

\author{
Immunological Aspects of Dermotropic and viscerotropic leishmaniaisis
}

\author{
Dara Karen Freire de Oliveira ${ }^{1}$ \\ Maria Eduarda Henrique da Silva Soares ${ }^{2}$ \\ Kalyne Monyque Lopes de Brito ${ }^{3}$ \\ Edvan Soares de Lira ${ }^{4}$ \\ Francisca Janaina Soares Rocha ${ }^{5}$
}

\begin{abstract}
Resumo: Objetivo: revisar os aspectos imunológicos das leishmanioses dermotrópicas e viscerotrópicas. Métodos: foi realizada uma revisão de literatura narrativa, através de artigos das bases de dados Pubmed, Scielo e BVS, utilizando os descritores: Leishmaniose cutânea, Leishmaniose visceral, Citosinas, Interleucinas e Imunologia. Foram utilizados critérios de inclusão estudo de revisão sistemática e ensaio clínico controlado. A amostra total gerou 436 artigos dos quais foram selecionados 22 artigos. Resultado: o principal mecanismo de controle da Leishmania é a imunidade celular, tanto inata quanto adaptativa. Entretanto anticorpos e o sistema complemento podem também destruir o parasito. O sistema imune inato atua confinando e reconhecendo o patógeno para produzir espécies reativas de oxigênio que podem causar a morte do parasita. O sistema imune adaptativo age tanto apresentando antígenos aos linfócitos $\mathrm{T}$ virgens como produzindo interleucina 12 . Considerações finais: a resistência e a susceptibilidade à infecção estão associadas ao nível de expansão de células Th1 e Th2, respectivamente. Com isso, o resultado clínico da infecção por Leishmania depende do equilíbrio entre as citocinas que ativam as células Th1 e Th2. Portanto, a diferença no combate a leishmaniose dermotrópica e viscerotrópica está na expressão do perfil TCD4 ${ }^{+}$ e suas citocinas produzidas.
\end{abstract}

Palavras-chave: Imunologia; Citocinas; Interleucinas; Leishmaniose cutânea; Leishmaniose visceral

\footnotetext{
${ }^{1}$ Acadêmica do Curso de Odontologia da Universidade Federal de Pernambuco. Recife, Pernambuco-Brasil. $\square$ darakaren2@gmail.com.. (D) https://orcid.org/0000-0001-6283-2863.

${ }^{2}$ Acadêmica do Curso de Biomedicina da Universidade Federal de Pernambuco. Recife, Pernambuco-Brasil. ma.eduardahenriquee@gmail.com. (D) https://orcid.org/0000-0002-8828-6255.

${ }^{3}$ Aluna do programa de Pós-Graduação do Departamento de Histologia e Embriologia da Universidade Federal de Pernambuco. Recife, Pernambuco-Brasil. $₫$ kalynemonyque@gmail.com. (D) https://orcid.org/0000-00034253-9533.

${ }^{4}$ Aluno do programa de Pós-Graduação do Departamento de Histologia e Embriologia da Universidade Federal de Pernambuco. Recife, Pernambuco-Brasil. $₫$ edvan.lira@ufpe.br. (D) https://orcid.org/0000-0002-7308-9339.

${ }^{5}$ Professora Associada de Parasitologia no Centro de Ciências Médicas da Universidade Federal de Pernambuco. Recife, Pernambuco-Brasil. $₫$ janaina.srocha@ufpe.br.. (D) https://orcid.org/0000-0002-7218-174X_.
}

Recebido em Aceito em Publicado em

06/02/2021 26/07/2021 03/09/2021


Abstract: Objective: To review, through bibliographies, the immunological aspects of dermotropic and viscerotropic leishmaniasis. Method: A narrative literature review was carried out through articles from the Pubmed, Scielo and VHL databases using the keywords: Cutaneous Leishmaniasis, Visceral Leishmaniasis, Cytokines, Interleukins and Immunology. Inclusion criteria such as systematic review study and controlled clinical trial were used. The total sample generated 436 articles, of which, through the inclusion criteria and an analysis of the compatibility of the proposed literature review, 22 articles were selected. Result: The main control mechanism of Leishmania is through cellular immunity, both innate and adaptive. Furthermore, both the antibodies and the complement system can also destroy the parasite. The innate immune system works by confining and recognizing the pathogen to produce reactive oxygen species that can cause the parasite to die. The adaptive immune system, on the other hand, acts both presenting antigens to naive Tlymphocytes and producing interleukin 12. Conclusions: Resistance and susceptibility to infection are associated with the level of expansion of Th1 and Th2 cells, respectively. Thus, the clinical outcome of Leishmania infection depends on the balance between cytokines that activate Th1 and Th2 cells. Therefore, the difference in combating dermotropic and viscerotropic leishmaniasis lies in the expression of the TCD4+ profile and its produced cytokines.

Keywords: Immunology; Cytokines; Interleukins; Cutaneous leishmaniasis; Visceral leishmaniasis.

\section{INTRODUÇÃO}

As leishmanioses são infecções tropicais causadas por espécies de protozoários do gênero Leishmania ${ }^{1}$. Estimativas sugerem que cerca de 1,6 milhões de novos casos ocorram por ano. Contudo, essa infecção, ainda, é bastante negligenciada, apesar de ser um sério problema de saúde, causando morbidade e mortalidade significativa em vários países distribuídos pela Europa, África, Ásia e América. A transmissão ocorre através da picada de flebotomíneos (Lutzomyia spp) fêmeas infectadas com o parasito ${ }^{2,3}$.

Durante o repasto sanguíneo, os promastigotas metacíclicos, formas infectantes de leishmania, são inoculados na derme e em seguida fagocitados pelas células fagocíticas, como macrófagos, células dendríticas e neutrófilos. Nos macrófagos, anteriormente monócitos da corrente sanguínea, os promastigotas sobrevivem e se transformam em amastigostas. Após se proliferarem, as formas amastigotas se multiplicam nos fagócitos, através de divisão binária, causando o rompimento da célula, e, assim, permitindo que os parasitos liberados infectem novos fagócitos. Os locais de disseminações dependem da espécie do parasito e de fatores intrínsecos dos hospedeiros, sendo o primordial o estado imunológico. Além do homem, mamíferos como roedores e cães são hospedeiros para algumas espécies de Leishmania ${ }^{4,5}$. 
De acordo com a forma clínica e as espécies do parasito, a leishmaniose pode se distinguir em dermatológica (LD) e visceral (LV) ${ }^{4}$. A Leishmaniose Dermatológica (LD) se restringe as formas clínicas que afetam a pele, correspondente a Leishmaniose Cutânea e Leishmaniose Mucocutânea. A Leishmaniose Cutânea pode ser causada pelas espécies dermotrópicas como a Leishmania tropica e Leishmania major, no Velho Mundo, e no Novo Mundo, pela Leishmania braziliensis e Leishmania amazonensis. A Leishmaniose Mucosa ou Mucocutânea, restrita à América do Sul, pode ser causada principalmente pelo subgênero Viania, como Leishmania (Viania) braziliensis e Leishmania (Viania) panamensis ${ }^{3}$.

A forma cutânea corresponde aproximadamente a $90 \%$ dos casos, sendo endêmica em 18 países da América, inclusive no Brasil, como exemplo, no estado do Rio de Janeiro 5,6,7. A Leishmania induz reação inflamatória granulomatosa, pois recrutam células do sistema imunológico sendo os linfócitos, plasmócitos e macrófagos, na forma dermotrópica. Clinicamente, essa reação na pele se apresenta em forma de úlceras localizadas, difusa ou disseminada, e na mucosa pode ser visualizada uma extensa destruição e ulceração desses $\operatorname{tecidos}^{1,5}$. A imunopatogênese da Leishmaniose Tegumentar Americana (LTA) é dependente da magnitude da resposta do sistema imunológico, de forma a afetar o resultado clínico e a classificação relacionada à duração da infecção aguda ou crônica ${ }^{2}$. O controle dessas lesões depende da resposta imune tipo Th1. A resistência e eliminação dos parasitos são mediadas por células como os linfócitos Th1 e pela produção de citocinas inflamatórias, tais como o Interferon-Gama (IFN- $\gamma$ ) e o Fator de Necrose Tumoral (TNF) $-\alpha$ e $-\beta$, enquanto que os linfócitos Th2 e as IL-4 e IL -10 estão ligados à susceptibilidade a infecção. No entanto, é necessário um equilíbrio na resposta imune, pois a exacerbação dos linfócitos Th1 produz um aumento da destruição tecidual que caracteriza a forma clínica mucocutânea e o predomínio dos linfócitos Th2 se relaciona a progressão da leishmaniose cutânea ${ }^{4,8,5,9}$.

A Leishmaniose Visceral (LV) é caracterizada por ser bastante grave e de alta mortalidade. É uma infecção sistêmica de células fagocíticas e possui uma intensa ativação da resposta inflamatória, causada pelo protozoário Leishmania donovani (no Velho Mundo) e Leishmania infantum/chagasi (Novo Mundo). Assim como na LD, a forma promastigota do parasito é fagocitada por células fagocíticas do hospedeiro, e se diferenciam em amastigota. Os principais órgãos acometidos são baço, fígado e medula óssea. Aproximadamente, 90\% dos pacientes não desenvolvem os sintomas, sendo assim, classificados em assintomáticos ou 
subclínicos. A incidência da doença é de pelo menos 0,2 a 0,4 milhões de casos em todo o mundo, causando 20.000-40.000 mortes a cada ano. Além disso, dados de estudos epidemiológicos indicam que apenas 1 em 5-10 indivíduos infectados desenvolvem a LV, sugerindo o número de indivíduos infectados-. Com isso, nota-se que os reservatórios de parasitos em potencial são bem maiores. Ao progredir, a infecção causa um aumento do baço, fígado e pode causar distúrbios hematológicos, como por exemplo: anemia, trombocitopenia, além de sangramento e neutropenia. Os pacientes, também, podem sofrer com perda de peso e febre. Indivíduos assintomáticos têm sua resposta imune caracterizada por uma resposta de células T contra a Leishmania que é demonstrada por Teste de sensibilidade tardia (DTH) positivo. Já os pacientes acometidos pela LV, com sintomas clínicos, apresentam comprometimento da produção de IL-2, IFN- $\gamma$ e IL-12 por meio de células T específicas, além de também apresentarem elevação de mediadores anti-inflamatórios como a IL-10, que auxilia na multiplicação do parasito e pode interferir no controle da infecção ${ }^{10}$.

Durante a LV ativa, o sistema imunológico não é suprimido, mas sim, altamente ativado e essa ativação provavelmente é induzida por antígenos Leishmania, podendo ocorrer, principalmente, nos órgãos onde os parasitos se desenvolvem, como por exemplo: baço, fígado e medula óssea ${ }^{10,11}$.

Portanto, objetiva-se, no presente estudo, revisar os aspectos imunológicos da Leishmaniose Dermotrópica e Viscerotrópica, destacando-se as semelhanças e diferenças.

\section{MÉTODOS}

Foi realizada uma revisão de literatura com base no bancos de dados PUBMED, SCIELO e BVS a respeito dos aspectos gerais do sistema imunológico no combate a Leishmaniose Dermotrópica e Viscerotrópica. A pesquisa foi analisada entre setembro e dezembro de 2020. Para melhor definição nos termos de busca nas bases selecionadas, foram empregadas, de acordo com os Descritores em Ciências da Saúde (Decs), as palavras-chave: Leishmaniose Cutânea, Leishmaniose Visceral, Imunologia, Citocinas e Interleucinas. A pesquisa resultou em 436 artigos, no entanto, somente 22 artigos foram selecionados com base nos critérios de inclusão estabelecidos: artigos de revisão sistemática, ensaio clínico controlado e, além disso, observou-se a atualidade e relevância a respeito da temática. 


\section{RESULTADOS}

\section{Mecanismos do Sistema Imunológico no combate às Leishmanioses Dermotrópicas e Viscerotrópicas}

O parasito aproveita os estágios iniciais da infecção para se estabelecer ou se desenvolver dentro do microambiente de seus hospedeiros, em contrapartida também é a chance do hospedeiro de montar uma resposta rápida e eficaz ao parasito, eliminando-o e controlando a infecção ${ }^{8,5}$.

A imunidade celular é o principal mecanismo de defesa do hospedeiro contra a Leishmania. Os anticorpos e o sistema complemento podem também destruir o parasito, agindo por meio da imunidade humoral. O controle da infecção por leishmaniose se faz por uma cascata de sinalização complexa e nela estão incluídas células do sistema imune inato como os macrófagos, monócitos, neutrófilos, além dos linfócitos $\mathrm{TCD}^{+}$da imunidade adaptativa, incluindo seus subgrupos Th1 e Th2. O sistema imunológico pode atuar de maneiras diferentes, dependendo da espécie de Leishmania ${ }^{11,12}$.

\section{Atuação do Sistema Imune Inato}

Após a entrada do parasito, o sistema imune inato exerce duas respostas para combater o patógeno. A primeira defesa do organismo do hospedeiro na Leishmaniose Tegumentar e Visceral é o confinamento do parasito no ambiente da infecção com o recrutamento das células inflamatórias no microambiente ${ }^{4}$. A segunda defesa do organismo compreende o reconhecimento dos patógenos pelos fagócitos através da interação entre os receptores de reconhecimento de patógenos (PPRs) com proteínas moleculares associadas ao patógeno (PAMPs). Isso promove a ativação de fatores de transcrição envolvidos na ativação de genes que codificam várias citocinas nas células apresentadoras de antígenos (APcs) e a produção de espécies reativas de oxigênio que são capazes de causar a morte do parasito $^{11,12}$.

\section{Principais células e funções na defesa inata}

Durante a defesa imune inata, as principais células são os neutrófilos, mastócitos, Natural Killer (NK) e monócitos. E, também, as células apresentadoras de antígenos (APcs) como células dendríticas e macrófagos ${ }^{13,1}$. 
As células NK são atraídas ao local da infecção e produzem IFN- $\alpha$ e $\beta$. Essas citocinas induzem uma atividade leishmanicida em macrofágos. As NK, também, produzem TNF- $\alpha$ e citocinas anti-inflamatórias como a IL-10, além de outras quimiocinas. como por exemplo, a quimiocina CCL2 $2,8,11$.

Os neutrófilos auxiliam o controle da carga parasitária ao fagocitar os patógenos nas formas promastigostas formando um fagolisossomo. Essas células secretam citocinas e quimiocinas como IL-8 e proteínas inflamatórias dos macrófagos como a MIP-1 $\beta$ que atraem mais neutrófilos e ativam os macrófagos, células dendríticas e linfócitos B para o local da infecção. Todavia, estudos apontam que, dependendo da espécie do parasito e do hospedeiro, os neutrófilos podem combater ou proteger os patógenos. Os neutrófilos ao fagocitarem e se infectarem com as formas promastigotas de Leishmania são fagocitados por macrófagos, que servem como células hospedeiras na multiplicação do parasito ${ }^{7,9,12}$. Dessa forma. esse processo envolvendo o macrófago e o parasito é conhecido como modelo “" "Cavalo de Tróia", 14 .

O combate dos neutrófilos na leishmaniose foi visto em estudos experimentais, na infecção por Leishmania braziliensis e L.amazonensis, pois os neutrófilos contribuiram no controle da infecção ao interagir com macrófagos infectados. Aproteção ao patógeno ocorreu na captação de neutrófilos apoptóticos por macrófagos e células denditricas, após a infecção por L. Major, possibilitando a diminuição da ativação de macrófagos e células denditrícas, resultando em uma melhor sobrevivência do parasito ${ }^{6,7,15}$. Também, outro estudo envolvendo a infecção por $L$. major, de lesões que não cicatrizam expressaram recrutamento aumentado e sustentado de neutrófilos, gerando o desenvolvimento de uma resposta do tipo $\mathrm{CD}^{+}{ }^{+} \mathrm{Th} 2$ no hospedeiro, logo, tornando-o suceptível a infecção por leishmaniose ${ }^{15}$.

Os mastócitos contribuem para o controle do parasito e promovem o influxo de células polimorfonucleares ao microambiente da lesão, quando infectados. Como consequência, as células polimorfonucleares liberam citocinas e enzimas que contribuem para a resposta imune inata e a migração dos macrófagos ${ }^{15,16,17}$.

Os monócitos reagem promovendo uma forte explosão respiratória, o que leva ao controle precoce da infecção, pois os parasitos são sensíveis a espécies reativas de oxigênio. O recrutamento dos monócitos é dependente do ligante CCL2, produzido pelas 
células no ambiente da infecção, após serem ativadas pelo fator de crescimento derivado de plaquetas $(\mathrm{PDGF})^{5,9}$.

Os macrófagos são ativados pelo Fator de Necrose Tumoral e Interferon-gama por meio da expressão da enzima Óxido Nítrico Sintase Induzida (iNOS). Essa enzima promove o aumento da produção de óxido nítrico e espécies reativas de oxigênio em macrófagos resultando na morte do parasito ${ }^{9,17}$. Nos estudos realizados, os camundongos deficientes em iNOS são considerados susceptíveis à infecção por L. major. Todavia, ainda, desenvolvem uma maior resposta de células Th1 comparando-se com os camundongos do tipo selvagem ${ }^{14}$. Enquanto IFN- $\gamma$ e outras citocinas inflamatórias, como o TNF, ativam macrófagos infectados para produzir óxido nítrico (NO), as células do subgrupo Th2 com suas citocinas relacionadas, como a IL-4, IL-3 e IL-10, além da produção de anticorpos, são associadas a macrófagos alternativos, que acabam suportando a sobrevivência do parasito dentro dos macrófagos, e uma possível não cura ${ }^{10,12}$.

As células dendríticas (DC) reconhecem, transportam e processam os patógenos $^{3}$. Assim, os mecanismos com maiores resoluções na resposta imune inata que combatem o parasito, antes da resposta imune adaptativa a todas Leishmania spp., são a produção de espécies reativas de oxigênio, que acontece na fagocitose pelas células fagocíticas e a produção do óxido nítrico ${ }^{15}$.

\section{Atuação do Sistema Imune Adaptativo}

Após a resposta inicial pelo sistema imune inato, é gerado um antígeno específico quando as células dendríticas epidérmicas captam o parasito e migram para os linfonodos regionais e se diferenciam em células dendríticas apresentadoras de antígenos. Algumas células dendríticas são residentes nos linfonodos, entretanto, a maioria delas é derivada de monócitos inflamatórios recrutados na lesão cutânea, sendo essas últimas que migram para o linfonodo de drenagem ${ }^{14}$. Essas células agem tanto apresentando esses antígenos aos linfócitos T virgens como produzindo Interleucina-12. A IL-12 ativa as células $\mathrm{NK}, \mathrm{CD}^{+}$e promove a diferenciação das células $\mathrm{T} \mathrm{CD}^{+}$, em linfócitos Th1, iniciando a resposta imune celular ${ }^{9,16,17}$.

\section{Principais células e funções na defesa adaptativa}


Os linfócitos Th1 se direcionam ao local da infecção e ao se instalar, aumentam a produção de Interferon-gama, Fator de Necrose Tumoral-alfa (TNF- $\alpha$ ) e Interleucina (IL-2). $\mathrm{O}$ IFN- $\gamma$ ativa os macrófagos e a Interleucina-12, promove o aumento da atividade leishmanicida ${ }^{15,16,18}$. Os linfócitos $\mathrm{TCD}^{+}$podem não estar uniformemente distribuídos nas lesões de Leishmaniose, consequentemente, não conseguem interagir com todas as células infectadas. No entanto, o IFN- $\gamma$ produzido age com um longo alcance de forma a estimular a produção de óxido nítrico pelas células infectadas, dessa forma, suprimindo a desigualdade da distribuição das células TCD4 ${ }^{+}$nas lesões ${ }^{15}$.

$\mathrm{O}$ perfil Th2 é estimulado por Interleucina-4. Os linfócitos $\mathrm{TCD}^{+} \mathrm{Th} 2$ produzem citocinas anti-inflamatórias como IL-4, IL-5, IL-10 e IL-13 ${ }^{18}$ que estão associadas com a suscetibilidade a infecções por Leishmania ${ }^{6,7,13}$. De maneira geral, a diferença entre resistência e susceptibilidade à infecção está associada ao nível de expansão de células Th1 e Th2, respectivamente ${ }^{15,18}$. Com isso, o resultado clínico da infecção por Leishmania depende do equilíbrio entre as citocinas ativadoras das células Th1 e Th2 ${ }^{1}$. Estudos da Leishmaniose Visceral demonstraram que as citocinas IFN- $\gamma$, IL-27, IL-10, IL-6 estavam associadas à hepatoesplenomegalia, neutropenia e trombocitopenia, e, níveis elevados de IL-6 está relacionado fortemente à morte ${ }^{12,19}$.

Estudos com L. braziliensis demonstram que, também, na resposta à leishmaniose cutânea e mucosa atuam um subtipo celular conhecido como Th17, relacionado com a produção de IL-17 que aumenta a produção de mediadores inflamatórios como IL-1, IL-6, TNF- $\alpha$ e NOS2. Eles agem auxiliando os linfócitos Th1 e Th2 quando há necessidade maior de uma inflamação tecidual por patógenos resistentes a ação do Th1 e Th2 ${ }^{15,18}$.

A IL-10, juntamente ao Fator de Transformação do Crescimento Beta (TGF-ß) e ácido retinóico, atuam na diferenciação das células regulatórias (Treg), e, assim, ativam o perfil Th $3^{18}$. Durante essa diferenciação, as células Th17 produzem interleucina-21 que amplifica a indução das células Th17. Para ocorrer a estabilização desse fenótipo, as IL-6 e IL-21 atuam promovendo a expressão de receptores da interleucina-23. A IL-23 é capaz de estabilizar as células Th1 $17^{18}$.

Outro fator interessante são as células $\mathrm{TCD}^{+}$, reguladas por células Th17, produzindo IL-17, que, além de ser pró-inflamatória, também, estimula a produção de outras citocinas com essas características, como TNF e IL-6. Cada citocina modula a resposta 
imunológica do hospedeiro frente ao parasito, de diversas formas, seja recuperando ou protegendo o sistema imunológico, através de TNF, IFN- $\gamma$, IL12, por exemplo. Ou, influenciando, positivamente, o parasito, através da indução de IL-10 que, por consequência, diminui os níveis de NO e $\operatorname{ROS}^{19.20}$. O parasito Leishmania, através da estimulação de uma resposta inflamatória, acaba influenciando na produção de várias citocinas e moléculas incluindo IFN- $\gamma$, IL-27, IL-10, IL-6, em que, essas citocinas estavam associadas à hepatoesplenomegalia, neutropenia e trombocitopenia. Níveis altos de IL-6, por exemplo, está fortemente associado à morte ${ }^{14}$.

As células Treg apresentam papéis diferentes na regulação da Leishmaniose Tegumentar (LT). Por exemplo, enquanto que na L. major as células Treg podem tornar os camundongos suscetíveis à infecção ou reativar uma infecção secundária, na L. amazonensis elas controlam as respostas imunopatológicas. Ademais, pesquisas em lesões crônicas na Leishmania panamensis ou L. braziliensis demonstraram que as células Treg estão prejudicadas ${ }^{15}$.

As células $\mathrm{TCD}^{+}$podem moldar a resposta imune adaptativa inicial à leishmaniose, produzindo IFN $\gamma$ em nódulos linfáticos. Isso irá depender da intensidade da infecção no inicio ${ }^{19}$. Pode-se observar que as lesões em camudongos foram curadas na ausência de células $\mathrm{TCD}^{+}$, depois de uma elevada dose de L.major No entanto, em lesões com baixas doses com duração prolongada, as células $\mathrm{TCD}^{+}$foram requisitadas $^{15}$.

Na leishmaniose cutânea, há também a produção de células T duplo-negativas contribuindo na imunidade por produzir IFN- $\gamma$, após o reconhecimento do antígeno MHC classe $\mathrm{II}^{15}$.

A infecção por leishmaniose leva a uma imunidade duradoura às reinfecções mediada por células TCD4 ${ }^{+}$. Há produção de células T efetoras de vida curta que promovem a morte dos parasitos persistentes e, porém, a célula $\mathrm{T}$ de memória efetora $(\mathrm{TEM})^{15}$. A leishmaniose pode induzir, também, a diferenciação de linfócitos $\mathrm{TCD}^{+}$em células $\mathrm{T}$ de memória central de vida longa (TCM) cuja função é proteger o hospedeiro de reinfecções ${ }^{14}$. Logo, a descoberta dessas células de memória pode fomentar a base de estratégias para fins de uma futura vacina ${ }^{15,21}$.

Células $\mathrm{TCD}^{+}$citotóxicas participam na progressão das lesões de $L$. braziliensis visto que, à medida que a lesão progride de não ulcerada a ulcerada, decresce a 
quantidade celular de $\mathrm{TCD}^{+}$e aumenta a de $\mathrm{TCD} 8^{+}$. Essas últimas, por sua vez, produzem granzimas que levam a perda da integridade da pele, dificultando, assim, a cicatrização das lesões ${ }^{15}$.

\section{Interação do Sistema Imune Inato e Adaptativo}

Os macrófagos ativados em função da interação com o parasito ou através das citocinas secretadas por Th1 passam a produzir óxido nítrico, além da produção de espécies reativas de oxigênio que são mediadas pelo IFN- $\gamma$, durante a fagocitose, sendo todo esse conjunto essencial para a eliminação do parasito intracelular, pois estão relacionados com resistência à infecção. Enquanto que o IFN- $\gamma$ e outras citocinas inflamatórias como o TNFativam macrófagos infectados para produzir NO, as células do subgrupo Th2, com suas citocinas relacionadas, como a IL-4, IL-5, IL-13 e IL-10, além da produção de anticorpos, são associados a macrófagos alternativos, que acabam suportando a sobrevivência do parasito dentro dos macrófagos, e uma possível não cura ${ }^{12,22}$.

O fator de crescimento transformador beta, , está relacionado à atividade leishmanicida do macrófago, já que essa citocina está relacionada com a desativação de macrófago e inibição da ação do IFN- $\gamma$. O TGF- $\beta$ atua mudando o padrão de resposta imune, com o aumento do RNA mensageiro para IL-10 e com isso favorecendo a infecção. Mas, em estudos realizados com animais susceptíveis, que foram tratados com anticorpos anti-TGF$\beta$, esses animais tornaram-se protegidos e apresentaram um aumento na expressão de RNAm para IFN- $\gamma$, além de influenciarem em uma diminuição do número de parasitos e melhora rápida de lesões e um aumento de NO, sugerindo que o TGF- $\beta$ tem um papel importante na supressão da produção de NO por macrófagos infectados. Outras células que atuam na reação imunológica, causada pelo parasito Leishmania, são os monócitos, que reconhecem o parasito por meio de outros monócitos infectados e acabam produzindo NO e ROS, além deles, também atuam as NK que produzem TNF e citocinas anti-inflamatórias como a IL-10, e são estimuladas por IL-12, além de outras quimiocinas como, a CCL2 que ajuda a ativar as células Th1 e ativam macrófagos. Já as células dendríticas desempenham um papel como células apresentadoras de antígenos. Com isso, quando o parasito é detectado por DCs acabam desencadeando a produção de IL-12, que controla a carga do parasito, além de manter 
o equilíbrio de Th1/Th2 e agir sobre as células NK, estimulando a produção de citocinas, principalmente IFN- $\gamma^{12,14,22}$.

\section{DISCUSSÃO}

A resposta imune à infecção por leishmaniose está intimamente relacionada com o controle ou desenvolvimento da doença e isso pode ser observado nas manifestações clínicas, pois pacientes com sintomas clínicos apresentam uma desordem na produção de IL2 , IFN- $\gamma$ e IL-12, além do aumento da IL-10, que ajuda na manutenção do parasito $^{10,11}$. O artigo XIV, também, demonstra que a imunopatogênese de ambas as leishmanioses dependem da magnitude do sistema imunológico, em que o controle da doença é caracterizado por células Th1 e a suscetibilidade por células Th2, quando se trata de uma imunidade adquirida ${ }^{14}$.

O estudo laboratorial em ratos revelou que essa relação do sistema imune inato e adaptativo desenvolveu uma maior resposta de células Th1, e, com isso, o aumento da produção de IFN- $\gamma$, TNF- $\alpha$ e IL-2, resultando em um maior controle da infecção por meio do aumento da atividade leishmanicida ${ }^{15}$. Todavia, foi observado na pesquisa do artigo VI, de pacientes com leishmaniose ativa, um aumento de citocinas como, IL-4 e IL-10 e o perfil Th2, causando, assim, um papel imunossupressor altamente associado com a suscetibilidade a infecções por Leishmania ${ }^{6}$. Dessa forma, apesar dos diferentes métodos de pesquisa implicase afirmar que a resposta contra o parasita depende de variáveis, tais como, a espécie de Leishmaniose e o estado imunológico do hospedeiro.

Além disso, alguns estudos observaram o subtipo celular Th17, que produz IL17 e aumenta a produção de IL-1, IL-6 e NOS2, agindo no auxílio dos linfócitos Th1 e Th2 quando se tem a necessidade maior de uma inflamação tecidual por patógenos resistentes a ação do Th1 e Th2 2,4,7,18. Mas, no estudo do artigo XV, diferente das células Th17, mostrou-se que a ação das células Treg podem tornar camundongos suscetíveis à infecção ou reativar uma infecção secundária ou podem controlar as respostas imunopatológicas a depender da espécie $^{15}$. Com isso, ainda há necessidade de aprofundamento sobre a função das células Treg e de que maneira elas podem ajudar no controle da Leishmaniose.

De maneira geral, a suscetibilidade ou resistência à infecção está relacionada intimamente a resposta imune mediada por células Th1 e Th2. Ademais, estudos são 
necessários para analisar as funções das células Treg e como elas podem contribuir no controle da Leishmaniose ${ }^{2}$.

O estudo limita-se quanto à abordagem e obtenção dos artigos base, tendo em vista que dos 436 artigos, $90 \%$ não estavam disponíveis ao acesso. Além disso, somente 22 artigos foram incluídos por meio dos critérios de inclusão, no presente artigo de revisão narrativa.

\section{CONSIDERAÇÕES FINAIS}

O combate à leishmaniose se faz através do Sistema Imune Inato e Adaptativo. A leishmaniose tegumentar que corresponde às formas clínica Cutânea e Mucocutânea e a Leishmaniose Visceral,compartilham do mesmo mecanismo inato correspondente ao confinamento do parasito pela atuação dos neutrófilos, monócitos e Natural killer, e, também, a produção de espécies reativas de oxigênio pelos macrófagos.

O sistema Imune adaptativo, no entanto, diferencia-se pela expressão do perfil $\mathrm{TCD}^{+}$. Enquanto que a leishmaniose tegumentar apresenta o perfil Th1 e suas respectivas citocinas pró-inflamatórias IL-2, TNF- $\alpha$ e IFN- $\gamma$, a leishmaniose visceral está relacionada com o perfil Th2 e as citocinas anti-inflamatórias produzidas IL-4, IL-5, IL-10, IL-13 e IL-6. O subtipo Th17 auxilia na imunopatogênese, através do aumento da inflamação tecidual nas lesões tegumentares e viscerais. Ademais, pesquisas sobre as células Treg, TCD8 ${ }^{+}, \mathrm{T}$ duplo negativo e células de memória, ainda, são incipientes para possibilitar comparações entre as formas clínicas dermotrópicas e viscerotrópicas.

Pelo exposto, fazem-se necessários novos estudos sobre a participação dessas células dentro de uma complexa rede de interligação com as células Th1 e Th2 que, juntas, irão orquestrar nosso sistema imunológico.

\section{AGRADECIMENTOS}

A Deus e família, pelo auxílio na realização do artigo. 


\section{REFERÊNCIAS}

1. FERRAZ, Raquel et al. CD3+ CD4neg CD8neg (double negative) T lymphocytes and NKT cells as the main cytotoxic-related-CD107a+ cells in lesions of cutaneous leishmaniasis caused by Leishmania (Viannia) braziliensis. Parasites \& Vectors, v.219, n.10, p.1-12, 2017.

2. HIPPÓLITO, Daise Damaris Carnietto et al. Expression profile of cytokines produced in biopsies from patients with American cutaneous leishmaniasis. Acta Trop, v.189, p.69-75, 2019.

3. TERRA, Rodrigo et al. Immunomodulation From Moderate Exercise Promotes Control of Experimental Cutaneous Leishmaniasis. Front Cell Infect Microbiol, v. 115, n.9, p.1-24, 2019.

4. MASPI, Nahid; ABDOLI, Amir; GHAFFARIFAR, Fathemeh. Pro-and antiinflammatory cytokines in cutaneous leishmaniasis: a review. Pathog Glob Health, v.110, n. 6, p.247-260, 2016.

5. COVRE, Luciana $\mathrm{P}$ et al. Circulating Senescent $\mathrm{T}$ Cells Are Linked to Systemic Inflammation and Lesion Size During Human Cutaneous Leishmaniasis. Front Immunol, v. 4, n.9, e:3001, 2019.

6. GOMES, Aparecida Helena Souza et al. American cutaneous leishmaniasis: In situ immune response of patients with recent and late lesions. Parasite Immunol, v. 39, n.4, p.1-27, 2017.

7. CUNHA, Clarissa $\mathrm{F}$ et al. Contribution of Leishmania braziliensis antigen-specific CD4+ T, CD8+ T, NK and CD3+CD56+NKT cells in the immunopathogenesis of cutaneous leishmaniasis patients: Cytotoxic, activation and exhaustion profiles. PLoS One, v. 15, n.3,e:0229400, 2020.

8. BOUSSOFFARA, Thouraya et al. Activated cytotoxic $\mathrm{T}$ cells within zoonotic cutaneous leishmaniasis lesions. Immun Inflamm Dis, v.7, n.3, p.95-104, 2018.

9. COSTA, Diego et al. CCR2 signaling contributes to the differentiation of protective inflammatory dendritic cells in Leishmania braziliensis infection. $J$ Leukoc Biol, v.100, n.2, p.423-32, 2013.

10. RODRIGUES, Vasco et al. Regulation of immunity during visceral Leishmania infection. Parasites \& vectors, v. 9, n.1, p.118, 2016.

11. BHOR, Renuka; RAFATI, Sima; PAI, Kalpana. Cytokine saga in visceral leishmaniasis. Cytokine, e:155322, 2020. 
12. FREITAS, José CC; PINHEIRO, Diana CSN. Aspectos celulares e moleculares da resposta imunitária a Leishmania spp. Revista Portuguesa de Ciências veterinárias, v.109, n.55, p. 11-20, 2010.

13. ARAUJO, Alexandra Paiva; GIORGIO, Selma. Immunohistochemical evidence of stress and inflammatory markers in mouse models of cutaneous leishmaniosis. Arch Dermatol Res, v. 307, n. 8, p.671-82, 2015.

14. SANTOS, Priscila L et al. The severity of visceral leishmanias is correlates with elevated levels of serum IL-6, IL-27 and CD14. PLoS neglected tropical diseases, v. 10, n.1, e:0004375, 2016.

15. SCOTT, Phillip; NOVAIS, Fernanda O. Cutaneous leishmaniasis: immune responses in protection and pathogenesis. Nat Rev Immunol, v.16, n.9, p.581-92, 2016.

16. BLACKWELL, Soel. Chemokines and leishmaniasis Divergent expression of inflammatory dermal chemokines in cutaneous leishmaniasis. Parasite Immunology, v.24, n.6, p. 295-301, 2018.

17. CONCEIÇÃO-SILVA, Fátima; MORGADO, Fernanda Nazaré; COUTINHO, Sergio G. A resposta Imune na Leishmaniose Tegumentar Americana ATIVA. In: Conceição-Silva F, Alvez CR, comps. Leishmaniose do continente americano. Rio de Janeiro: Editora FIOCRUZ, p. 357-379, 2014.

18. ALMEIDA, Amanda Ferreira. Avaliação da produção de citocinas th17, th1 e th2 por linfócitos $\mathrm{t}$ em pacientes com leishmaniose tegumentar americana [Dissertação de Mestrado]. Recife: Centro de Pesquisas Aggeu Magalhães, Fundação Oswaldo Cruz, 2013.

19. VASCONCELOS, Tassia Cristina Bello et al. Parasite load, iNOS and cytokine profiles, and histopathological aspects of Leishmania infantum infection in dogs with diferente clinical presentations. Ciência Rural,v. 49, n.10, 2019.

20. COSTA, Aline Silva Andrade et al. Cytokines and visceral leishmanisis: a comparison of plasma cytokine profiles between the clinical forms of visceral leishmaniasis. Memórias do Instituto Oswaldo Cruz,v. 107, n.6, p.735-739, 2012.

21. OLIVEIRA, Walker Nonato et al. The role of inflammatory and anti-inflammatory cytokines in the pathogenesis of human tegumentary leishmaniasis. Science Direct, v. 66, n.2, p. 127-132, 2014.

22. BACELLAR, Olívia; CARVALHO, Edgar M. Imunopatogênese da leishmaniose visceral. Gazeta Médica da Bahia, v.74, n.1, 2008. 